\title{
Apontamentos Históricos sobre a educação marista na cidade de Curitiba (1924 a 1985)
}

\author{
Danyelle Vallin Stropa ${ }^{1}$
}

Alexandra Ferreira Martins Ribeiro ${ }^{2}$

Alboni Marisa Dudeque Pianovski Vieira ${ }^{3}$

\section{Resumo}

Este estudo trata da atuação dos Irmãos Maristas, a partir de sua chegada ao Brasil e de sua vinda ao Paraná, no início do século XX. Como objetivo, procurou-se destacar os documentos guardados no Memorial Marista, que contribuem para apontamentos históricos sobre a atuação da Instituição Marista na educação, em Curitiba. Para tanto, abordou-se o processo histórico de constituição e desenvolvimento das primeiras escolas implantadas em Curitiba - o Instituto Santa Maria e o Instituto Paranaense -, bem como de que forma é constituída a Educação Marista nos documentos da instituição no Paraná. A pesquisa teve abordagem histórica, sendo de caráter bibliográfico e documental. O apoio teórico e metodológico foi buscado em Le Goff (2013).

Palavras-chave: História da Educação; Instituto Marista; Paraná.

\section{Historical Notes on Marist Education in the City of Curitiba (1924 to 1985)}

\section{Abstract}

This study deals with the work of the Marist Brothers, since their arrival in Brazil and their arrival in Paraná, at the beginning of the 20th century. As an objective, we tried to highlight the documents kept in the Marist Memorial that contribute to historical notes on the performance of the Marist Institution in education, in Curitiba. To this end, the historical process of constitution and development of the first schools implanted in Curitiba, the Santa Maria Institute and the Paranaense Institute, was addressed, as well as Marist education is constituted in the institution's documents in Paraná. The research had a historical approach, being bibliographic and documentary. Theoretical and methodological support was sought in Le Goff (2013).

Keywords: History of Education; Marist Institute; Paraná.

\section{Introdução}

O presente artigo versa sobre a atuação dos Irmãos Maristas no Brasil, em especial da chegada dos primeiros Irmãos no estado do Paraná, no início no século XX. Esses marcadores da presença Marista são elementos importantes para analisar e compreender em que momento histórico as primeiras escolas Maristas foram implementadas na região.

\footnotetext{
${ }^{1}$ Pontifícia Universidade Católica do Paraná, Curitiba, danyvallinstropa@gmail.com.

2 Pontifícia Universidade Católica do Paraná, Curitiba, alexandrafmribeiro@gmail.com.

${ }^{3}$ Pontifícia Universidade Católica do Paraná, Curitiba, alboni@alboni.com.
} 
No período escolhido, acontece um dos marcos importantes para o Instituto Marista no Brasil, identificado com base em duas linhas: a primeira com a chegada dos Irmãos no país, e a segunda com a instalação de um negócio já conduzido por eles na França, mas que também vem para o Brasil, a denominada editora FTD e seus primeiros impressos. Ela se instala em São Paulo, mais precisamente em Guarulhos, em um primeiro momento com impressos institucionais e aos poucos se expande para o público externo. Essa atuação constitui-se como solo fértil para a expansão no campo educacional de forma direta e indireta, ou seja, na abertura de novas escolas, como também na produção de impressos que adentrariam o espaço escolar a partir de conteúdos sistematizados por meio dos livros didáticos.

Documentos oriundos desse período são encontrados e mantidos pelo Memorial Marista, um centro de memória e referência da província Marista Centro-Sul (Grupo Marista) e no Centro Marista Champagnat (CMC), local de residência de alguns Irmãos, no qual se pode encontrar o itinerário de 200 anos de ação do Instituto na educação. Outras fontes são mantidas pela Casa da Memória de Curitiba e pelo Instituto Histórico e Geográfico do Paraná. Os documentos, no período compreendido entre 1924 e 1985, variam entre recortes de jornais, cadernetas escolares, fotos, circulares entre Irmãos e memorial da instituição, os quais possibilitam analisar a memória construída pela instituição e suas interfaces com o tempo histórico.

Como objetivo, procurou-se destacar os documentos guardados no Memorial Marista, que contribuem para apontamentos históricos sobre a atuação da Instituição Marista na educação, em Curitiba. Para tanto, analisou-se o processo histórico de constituição e desenvolvimento das primeiras escolas implantadas em Curitiba - o Instituto Santa Maria e o Instituto Paranaense -, bem como a constituição da educação Marista nos documentos da instituição no Paraná. A pesquisa teve abordagem histórica, sendo de caráter bibliográfico e documental. O apoio teórico e metodológico foi buscado em Le Goff (2013).

Nessa construção do pensamento, a história, por meio de suas memórias sistematizadas, possibilita um mergulho no tempo. Segundo Certeau (1982), ressuscitamos o passado, ou seja, retornamos a um mundo vivido, à outra época, cujo registro retorna ao presente. Por meio do estudo e da análise de fontes, o passado recebe novas interpretações, oriundas dos questionamentos do pesquisador. A memória sistematizada tem sido um instrumento de grande 
relevância à pesquisa historiográfica, pois, quando se escreve sobre o vivido, o registro torna-se história ao longo do tempo e possibilita novas interpretações, ampliando a capacidade de olhar o ontem.

A pesquisa, nesse tipo de documentação, exige do pesquisador alguns cuidados durante a seleção e a análise. Ao optar por trabalhar com essas fontes da memória, os monumentos, que são a herança do passado, passam a ser os documentos selecionados pelo historiador para a construção científica da história, segundo explica Le Goff (2013). Durante a análise dessas fontes, é necessário considerar os interesses de grupos em construir uma memória, observar as intencionalidades na produção e arquivamento de documentos. Nesse sentido:

[...] o documento não é inócuo. É, antes de mais nada, o resultado de uma montagem, consciente ou inconsciente, da história, da época, da sociedade que o produziram, mas também das épocas sucessivas durante as quais continuou a viver, talvez esquecido, durante as quais continuou a ser manipulado, ainda que pelo silêncio. O documento é uma coisa que fica, que dura, e o testemunho, o ensinamento (para evocar a etimologia) que ele traz devem ser em primeiro lugar analisados desmistificando-Ihe o seu significado aparente (LE GOFF, 2013, p.496497).

O documento é um monumento e cabe ao historiador entendê-lo como uma produção da sociedade que o elaborou e preservou, tanto para exprimir uma verdade, quanto para moldar uma representação do passado.

Para compreender as intencionalidades que podem ser desveladas nos documentos, fazse necessário compreender a constituição dessa instituição de educação. Nesse sentido, é preciso conhecer em que contexto ela nasce na França, as influências sofridas e as frentes de atuação que deram origem às missões nos vários países nos quais os Irmãos seguiram como missionários. Para isso, articular missão e fonte de recurso gerou uma necessidade na implantação das primeiras escolas Maristas, já que elas precisaram absorver o processo formativo dos Irmãos, o que corroborou para o surgimento de escolas em regime de internato, pois também eram casas de formações para os jovens Irmãos. Na França, essa modalidade de ensino era encarada como uma estratégia, principalmente no que se refere às bases de luta por justiça social e por uma escolaridade desenvolvida. 


\section{O contexto social francês e suas marcas na criação do Instituto Marista}

O idealizador da pedagogia marista, Marcelino Champagnat, nasceu em Marlhes, na França, em 1789. Vieira (2014) narra que, no povoado em que ele vivia, a maioria dos jovens e adultos era analfabeta. "Sabe-se que Champagnat, igualmente, sem possuir formação intelectual adequada, mas dotado de bom senso, força de caráter e determinação, logo após liberada a abertura de seminários, ingressou no seminário menor de Verrières, em 1805" (VIEIRA, 2014, p.24). Marcelino completou seus estudos no seminário maior de Lyon, local no qual recebeu influência religiosa e espiritual de sacerdotes que vivenciaram a Revolução Francesa.

Marcelino Champagnat nasceu e vivenciou a Revolução Francesa. De acordo com Chartier (2009), um dos pontos em que pode ser descrita a Revolução Francesa inscreve-se no âmbito religioso: por um lado, houve uma ruptura com a tradição cristã ou qualquer credo religioso, que se espalhou por todas as classes da nação; de outro lado, aumentou-se a crença na virtude inata do homem. Tal revolução cultural se fez sentir em perseguição a fiéis e em práticas cotidianas.

Nos documentos de Giusto (2007) e União Marista do Brasil (2010), a Revolução Francesa é representada como impactando as motivações para abertura do Instituto devido às consequências das perseguições religiosas sofridas pela família de Champagnat. No entendimento de Giusto (2007), a experiência vivida ao longo da Revolução pela família de Marcelino Champagnat e as marcas deixadas por ela e vivenciadas por ele no período escolar despertaram nele o desejo de criar um Instituto voltado à educação. Outro momento que é representado como relevante para que Marcelino tivesse a motivação de construir um local no qual pudesse ensinar crianças e jovens a ler, escrever e a conhecer Jesus Cristo é narrado por União Marista do Brasil (2010) ${ }^{4}$. Dessa forma, percebemos que as representações acerca das motivações para a fundação do Instituto Marista por parte de Marcelino se dão, nos documentos, como sendo de cunho religioso, ligados à sua fé.

\footnotetext{
${ }^{4}$ Para União Marista do Brasil (2010), no dia 28 de outubro de 1816, um fato mexeu com Champagnat e o levou a aplicar o seu sonho de instituir uma congregação de Irmãos. O jovem eclesiástico foi conhecido depois de visitar à casa de carapina em Les Palais, um povoado que ficava pouco depois de Le Bessat, no qual vivia um moço de 17 anos, Jean-Baptiste Montagne, que agonizava. "Tal circunstância tocou profundamente o coração" de Marcelino que viu "Nos olhos daquele rapaz, vislumbrou o clamor de milhares de crianças e jovens que, como ele, eram vítimas de trágica miséria humana e espiritual" (UNIÃO MARISTA DO BRASIL, 2010, p. 29).
} 
Entretanto, o documento que retrata a "missão educativa", elaborado por Alves (2011), narra que para a solicitação de abertura junto ao governo francês, Marcelino expressou seu desejo de educar jovens do campo para reeducação e manutenção da moral e dos bons costumes. Nesse documento, percebemos que as motivações representadas e direcionadas ao governo francês estavam em consonância com o regime político do período. Impulsionar a educação de jovens do campo era, também, parte do projeto de "Liberdade, Igualdade e Fraternidade" proferido pela Revolução Francesa.

A Revolução na França foi um momento impulsionado pela burguesia e validado pelo povo. Segundo Soboul (1989), a bandeira da revolução defendia um país mais desenvolvido e uma economia equilibrada. A luta era por mudança, com vistas a desonerar o alto custo de vida que sobrecarregava o povo e favorecia as categorias sociais abastadas. Esse cenário, marcado por múltiplos acontecimentos, contribuiu para o endividamento do Estado e culminou no evento ápice da Revolução, em 1789. Destaca-se que o desejo que impulsionou essa Revolução foi a constituição de uma sociedade com oportunidades para todos e melhores condições para se viver e suprir as necessidades básicas.

Uma das necessidades básicas estava ligada à educação elementar para a maioria da população francesa. De acordo com Razzini (2008), o processo de substituição do trabalho artesanal pelo trabalho assalariado e a implantação dos Estados Nacionais Modernos faziam com que a propagação da escola elementar fosse uma necessidade para consolidar tais projetos de nação. Para tanto, reformas na educação foram necessárias, como a utilização do ensino mútuo e o simultâneo, bem como a introdução de ferramentas educacionais que viabilizassem mais rápida e generalizadamente a educação elementar.

Com representação de um cenário contraditório de perseguição e necessidade, a instituição Marista foi fundada em 2 de janeiro de 1817. Marcelino Champagnat reuniu jovens com os mesmos ideais e ofereceu uma formação religiosa, constituindo, assim, um grupo de jovens Irmãos, chamados de Pequenos Irmãos de Maria, posteriormente denominados Irmãos Maristas.

As perseguições aumentaram depois das primeiras escolas implantadas na França, o que fez com que os Irmãos Maristas expandissem suas escolas do Instituto em outros países. De acordo com Giusto (2007), com a chegada de Luís Filipe de Orleans, os religiosos passaram a ser 
perseguidos e, em grande maioria, mortos, o que levou uma parcela significativa de Irmãos a rumar para outros continentes. Nesse período, os Irmãos passaram a ter cautela, diminuíram os encontros religiosos e seguiram a orientação de evitar o uso da batina na rua.

É possível identificar, nos registros históricos encontrados, que Marcelino Champagnat, fundador da Ordem, é representado como um homem que agia com cautela ao longo dos tempos difíceis e que suas preocupações eram registradas em seus rascunhos e cartas enviadas aos outros Irmãos. Aqui podemos fazer um destaque sobre a importância de toda e qualquer forma escrita que gere comunicação e deixe pistas investigativas para o processo de análises e olhares acerca do passado. Vieira $(2013$, p.71) corrobora ao afirmar que os "[...] documentos escolares oficiais (correspondências, ofícios e requerimentos, diários oficiais, relatórios, levantamentos estatísticos, pareceres, decretos) fornecem ao historiador a visão do poder público, dos órgãos diretores, das normas do que deveria ser realizado na escola". Com esses documentos produzidos e guardados pelo Instituto Marista, é possível esboçar a história da instituição e as intencionalidades dos registros.

Na constituição do Instituto Marista, os registros, principalmente os de Marcelino Champagnat, eram documentos utilizados como instrumentos para a comunicação e consolidação das regras, em especial as que direcionavam para a abertura das novas escolas. Podemos perceber que as cartas enviadas aos Irmãos atuavam como meio de comunicação e como diretrizes de processos, as quais necessitam ser seguidas e constituíam os alinhamentos da instituição.

No intuito de estabelecer sintonia e alinhamento, o Instituto Marista concebe o documento Guia das Escolas, publicado em 1853, com as diretrizes educacionais desejadas, bem como a conduta dos Irmãos nas funções da escola, um dos marcos da instituição naquela época e fonte de referência até os dias atuais para a constituição das escolas Maristas. O Guia das Escolas foi o primeiro documento oficial impresso que descreveu o pensamento pedagógico e educativo dos Irmãos Maristas e buscava responder às urgências do Instituto Marista nos primórdios da Revolução Industrial. O documento foi escrito em quatro seções, sendo a primeira sobre a "Educação", a segunda tratava da "Disciplina, Ensino e Organização", a terceira acerca do papel do "Educador" e a quarta e última parte tratava de uma abordagem sobre a "Metodologia do Ensino". De acordo com Furet et al. (2009), Marcelino Champagnat tinha a preocupação de formar os Irmãos para melhor ensinar às crianças e aos jovens da comunidade, 
para que realmente ocorresse uma aprendizagem significativa. O Guia das Escolas Maristas, traduzido por Furet et al. (2009), no ano de 1853, aborda a gestão dos colégios e o conteúdo das disciplinas escolares ofertadas, além de tratar da responsabilidade de execução por parte dos Irmãos. O guia foi editado seis vezes em francês, tendo a última edição publicada em 1946. A tradução brasileira, lançada em 2009, faz referência à edição de 1932.

Compreendemos que esse material com as diretrizes não foi concebido como instrumento teórico, mas como manual prático acerca do cotidiano escolar e que contribuía para a formação continuada dos Irmãos Maristas. Ademais, entende-se esse manual como um material de diretrizes que deveriam ser seguidas de forma estrita, alinhando o pensamento dos Irmãos com os demais integrantes da hierarquia.

Para tanto, considera-se que o espaço da escola foi assumido institucionalmente como lugar de formação dos sujeitos que atuariam em sociedade, considerando esse cenário propício à manifestação cultural e às relações entre o ser e o agir, práticas que marcam os valores inculcados na pedagógica impulsionada por Marcelino Champagnat. Por meio das diretrizes do Guia das Escolas Maristas, os valores, a missão e a tradição Marista foram se imprimindo nos sujeitos formadores na tentativa de repasse para aqueles que eram formados.

\section{A chegada dos Irmãos Maristas no Brasil e no Paraná}

Os primeiros registros dos Irmãos Maristas no Brasil são datados de 1897, na cidade de Congonhas do Campo, no estado de Minas Gerais. Nesse período, a educação ainda era acessada pela minoria da população, mas, no início do século XX, passou a ser entendida como elementar para o progresso da sociedade.

O papel da educação nesse período foi dimensionado pelos organismos políticos, que viam a possibilidade de vitalizar o organismo nacional e constituir a "nação" ancorada na ordem e no progresso. As paulatinas mudanças ocorridas em meados do século XIX, dentre elas a passagem de um modelo de sistema agrário para um urbano industrial, o aumento demográfico e a alteração da sociedade estamental para uma sociedade de classes promoveram transformações no setor cultural e o abandono dos antigos ideários. "A escola foi, em consequência, reafirmada como arma de que dependia a superação dos entraves que estariam 
impedindo a marcha do Progresso, na nova ordem que se estruturava" (CARVALHO, 1989, p.7). Em meio a essas transformações - nos níveis econômicos, sociais, culturais e políticos - a escola, ou a escolarização, passou a ser compreendida como um dos elementos do sistema cultural e como ferramenta que procurou favorecer ou dificultar essas mudanças. Os entusiasmos pela educação pairavam nos discursos políticos, mas não conseguiam atingir de forma quantitativa a população.

É nesse cenário de efervescência para questões educacionais que os Irmãos Maristas chegaram ao Brasil e foi nesse contexto que surgiram as primeiras escolas. Diante da imensidão territorial do Brasil, a instituição optou por se dividir em três unidades administrativas: Província Marista Brasil Centro-Norte, fundada em 1897; Província Marista Brasil Sul (Rede Marista do Rio Grande do Sul), fundada em 1990; e a Província Marista Brasil Centro-Sul, em 2002, passando em 2012 a denominar-se Grupo Marista. Segundo os documentos, a divisão possibilitou a expansão a partir de um processo fluído e seguro, no que diz respeito ao acompanhamento e à administração econômico-financeira das escolas Maristas. Em 1902, a Editora FTD é instituída no Brasil, frente de atuação editorial já praticada em outros países em que existia a presença Marista, fonte de registro importante na constituição da memória do Instituto. Percebe-se, no entanto, que a denominação "Grupo" marca fortemente o caráter empresarial assumido pelo trabalho desenvolvido pelos Irmãos.

Primeiramente, os Irmãos selecionaram jovens que pudessem atuar no Instituto. De acordo com as fontes, apesar dos desejos de expansão no campo educacional, as primeiras iniciativas versaram sobre a constituição de coletivos de jovens com interesse de viver a vida religiosa, compondo, assim, as casas de formações para os futuros Irmãos Maristas.

Podemos compreender essa ação de duas maneiras: primeiro, ainda não havia se consolidado na população a necessidade pela educação e, segundo, era necessário formar os Irmãos que iriam ministrar as aulas segundo as diretrizes do Instituto. Giusto (2007) relata que, ao longo da história do Instituto, muitos foram os documentos de cunho institucional que circularam por todas as províncias, a fim de uma condução alinhada ao que se desejava concretizar, mas, para a abertura de uma escola, as regras seguidas eram as estabelecidas pelos escritos de Champagnat. Dessa forma, é compreensível que a primeira iniciativa foi a busca e a formação de seu contingente de colaboradores. 


\section{A primeira escola na região de Curitiba}

A memória acerca da vinda dos Irmãos Maristas para Curitiba é narrada nos documentos que descrevem que o Bispo Dom João Francisco Braga fez o convite para que os Irmãos Maristas assumissem a gestão do Juvenato de Curitiba, sabedor da intenção de abertura de um colégio por eles. No Memorial Marista consta que, em setembro de 1924, o Irmão Exuperâncio acertou com o bispo de Curitiba a aquisição do imóvel, localizado na Rua XV de Novembro, número 904, para a construção do Colégio Marista. De qualquer maneira, a memória contida e construída nesse documento acerca da fundação do Colégio Marista liga-se aos interesses da Igreja e com o consentimento das autoridades locais católicas.

No que tange ao Juvenato de Curitiba, um documento que discorre acerca da origem do local, datado de 1924, auxilia na compreensão da história da instituição. Essa foi a primeira unidade Marista instituída, a qual contou com a participação de sete jovens em formação, os primeiros recrutados em Santa Catarina e alguns Irmãos cuja responsabilidade era atuar na formação e educação dos juvenistas, entre outros serviços. Giusto (2007) reitera que os estabelecimentos que viessem a abrigar fundações maristas deveriam assegurar local adequado para os Irmãos e oferecer espaço para aulas. Essas instalações deveriam ser obtidas por meio de parcerias entre a instituição e os municípios em que ocorreriam as fundações, pelo menos um ano antes da abertura do colégio. O Juvenato de Curitiba serviu como um centro de moradia e de formação aos Irmãos antes da abertura do colégio.

Nesse período, o Estado não conseguia atender a toda a demanda para a gradativa expansão da educação no país. No entendimento de Schelbauer e Corrêa (2019):

A expansão da escola primária no Estado do Paraná, como em outros Estados do Brasil, no período de 1930 a 1961, resulta não somente de um imperativo posto, de um lado, pela obrigatoriedade de oferta em segmentos populares, de saberes elementares necessários a inserção no processo de cidadania modernizador, mas, de outro e articulado a este, o imperativo de inserção de uma população jovem no mercado de trabalho (SCHELBAUER; CORRÊA, 2019, p.55).

Compreende-se que a fundação do Instituto Marista em Curitiba alinhava-se ao período em que a educação passava a ganhar nova significação no país. 


\section{HSE}

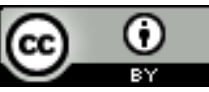

No que se refere ao primeiro diretor da instituição, há divergência entre as fontes. No Memorial Marista consta que o Instituto Santa Maria foi fundado em 15 de janeiro de 1925, tendo como seu primeiro diretor o Irmão Pedro Senador e como vice-diretor o Irmão Mário Odorico; o Irmão Henrique Augusto é citado como um colaborador nas atividades de formação do Juvenato e da educação das crianças. Porém, em entrevista concedida ao jornal Gazeta do Povo (COLÉGIO, 1985), em comemoração ao $600^{\circ}$ aniversário do Colégio Santa Maria, o Irmão Celedônio Cruz corroborou a data de inauguração, 15 de janeiro de 1925, acrescentou o número de 102 alunos e 6 Irmãos Maristas como professores no momento de fundação, mas atribuiu a direção do prédio localizado na Rua XV de Novembro, 904 ao Irmão Henrique Augusto. Percebemos que a narrativa do Irmão Celedônio apresenta dados discordantes da versão apresentada nos documentos constantes do Memorial.

O Instituto Santa Maria, no momento de sua fundação, localizava-se no centro de Curitiba, em prédio com janelas arejadas, como demonstra a primeira foto tirada do Instituto Marista em Curitiba, situado na Rua XV de Novembro.

Figura 1 - Foto do Instituto Marista em Curitiba, supostamente registrada no ano de 1925, situado na Rua XV de Novembro

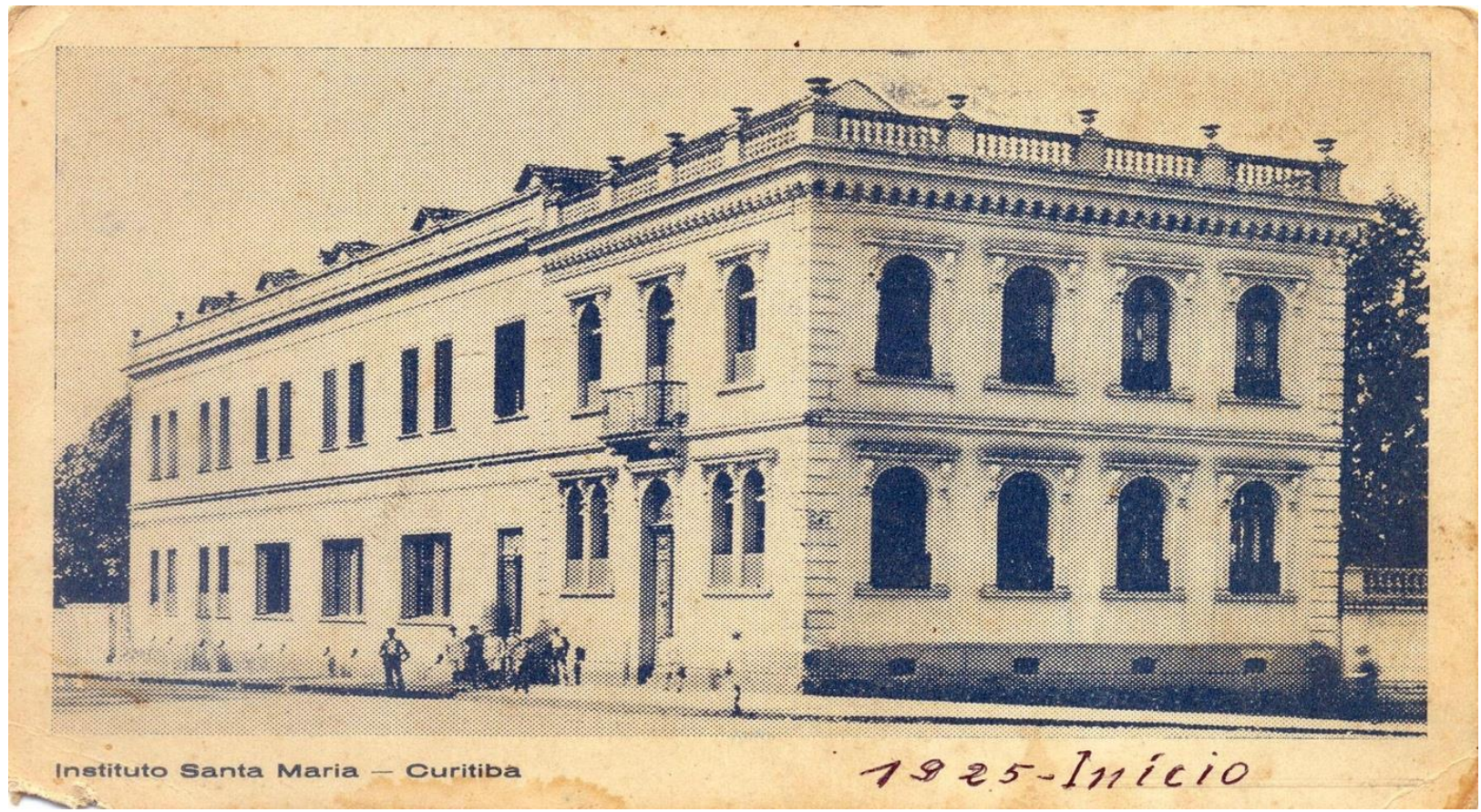

Fonte: Acervo do memorial Marista da Província Brasil Centro-Sul, Curitiba. Acesso em 2019. 
A imagem acima faz referência ao Instituto Santa Maria, localizado na Rua XV de Novembro, no centro de Curitiba, e pode ser encontrada preservada no Memorial Marista. Tratava-se de um local privilegiado, já que enquanto nos arredores do centro núcleos populacionais se formavam lentamente, ali era onde a cidade florescia. Vieira (2017) complementa que a Rua XV de Novembro era o local dos bondes elétricos, dos eventos, das principais lojas, dos cafés, dos clubes, dos teatros, além de ser o ponto de principal atenção do governo, que, no período entre 1920 e 1928, transformou-o em verdadeiro canteiro de obras. Por esse prisma, percebemos que a localização do majestoso prédio estava disposta em uma área nobre da cidade, local em que as famílias de classe média alta concentravam-se.

Os documentos descrevem que o Irmão Frumêncio saía em busca de novos jovens para compor seus docentes e seu quadro discente. De acordo com Bonato (19[?]), Frumêncio, no ano de 1925, em seus momentos de folga, visitava colônias vizinhas (Santa Cândida, Santa Felicidade, Colombo, Colônia Antônio Rebouças, entre outras), visando anunciar a presença Marista nessas comunidades e selecionar jovens com interesse de seguir o caminho religioso e de se tornarem futuros educadores, além de pesquisar o interesse de pais em terem seus filhos como futuros alunos no colégio. A memória constituída narra que no início foi necessário sair tanto em busca de educadores como de alunos.

Nos primeiros anos da instituição, somente os próprios Irmãos atuavam como professores e mantinham a gestão do colégio. Somente no ano de 1933 aparece nos registros o primeiro leigo como professor. Em 1978, foi dado início aos cursos de jardim de infância e ao pré-primário, no período da tarde, e professoras assumiram essa tarefa (SANTA MARIA, 1979). Observa-se que ao longo das décadas e conforme as necessidades, a instituição foi se adaptando aos novos desafios da comunidade. Com a expansão dos colégios e do número de alunos, percebemos também o aumento de leigos atuando na instituição.

\section{A docência e o regime interno}

Com base na análise da caderneta escolar datada de 30 de março de 1940, foi possível traçar um pequeno esboço do regimento da instituição, que foi expresso nesse documento. De acordo com Viñao-Frago (2008), esse tipo de material desvela a história do currículo; das 


\section{HSE}

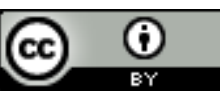

instituições educativas; das disciplinas; das atividades e dos exercícios escolares, dentre outras possibilidades de análises. Na caderneta, datada de 1940, os valores confessionais da instituição faziam-se fortemente presente, assim como demais elementos que demonstram a distinção do documento.

A caderneta pode ser considerada como elemento de distinção por se tratar de um documento escolar confeccionado exclusivamente para aquela instituição. Podemos observar que ela traz em sua capa de cor azul-marinho o símbolo Marista e o nome Instituto Santa Maria. A página de abertura da caderneta pode ser vislumbrada na Figura 2.

Figura 2 - Página de abertura da Caderneta Escolar, Instituto Santa Maria (1940)
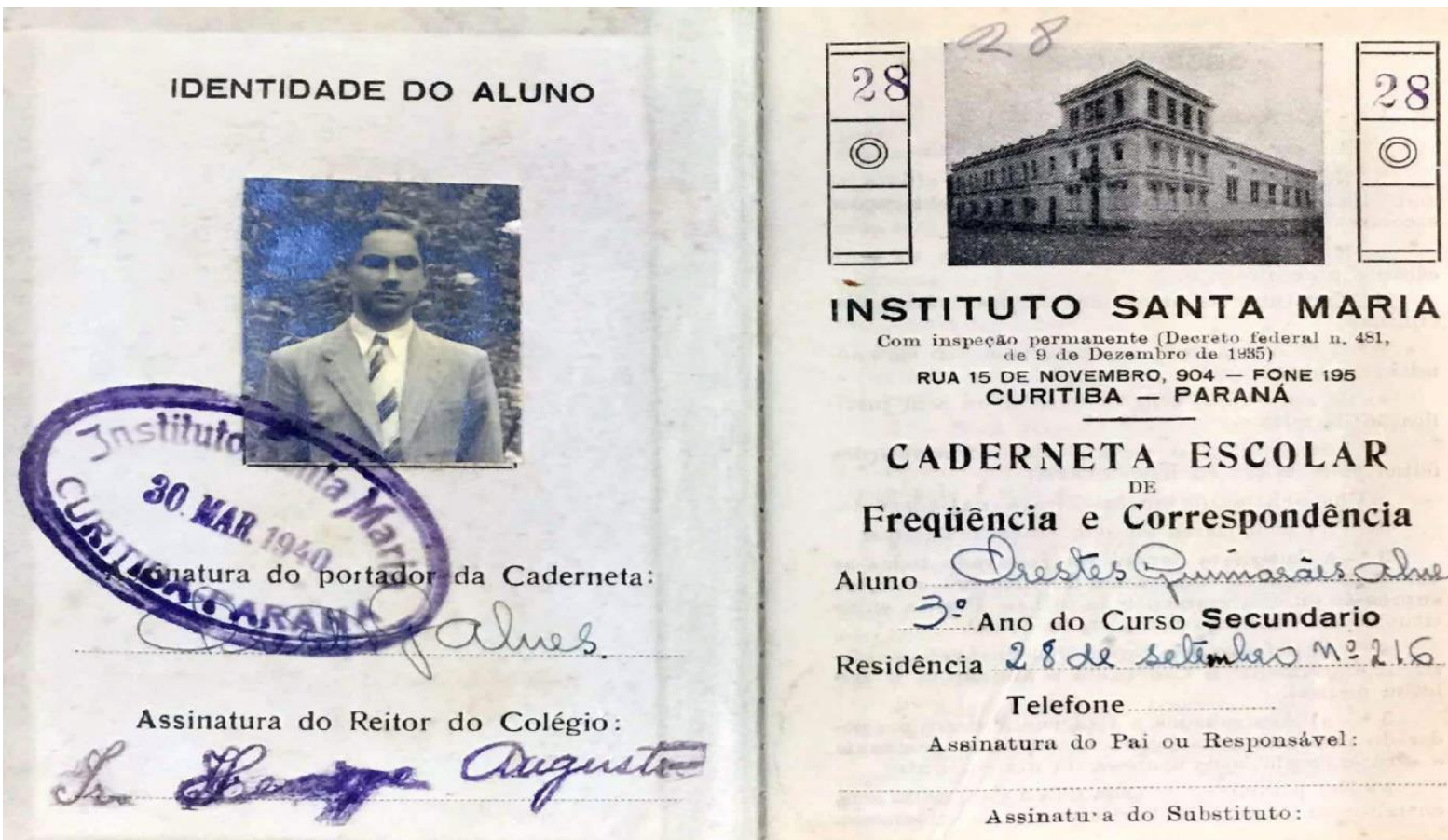

Com inspecan permanente (Decreto federal n, 481, RUA 15 DE NOVEMBRO, 904 - FONE 195
CURITIBA - PARANA

CADERNETA ESCOLAR Frequiência e Correspondência Aluno Prestes Pumaraies aluses 3:- Ano do Curso Secundario Residência 28 de setémbro $n=2.6$ Telefone

Assinatura do Pai ou Responsável:

Assinatu.a do Substituto

Fonte: IHGPR, Caderneta escolar de Orestes Alves: Coleção Pórcia Guimarães Alves. Imagem digitalizada pelas autoras.

Conforme pode ser observado na imagem, na primeira página da caderneta, algumas informações são valorizadas. O estudante vestindo terno para a imagem que compõe a identidade escolar; a assinatura do estudante e logo abaixo a assinatura do reitor; o imponente prédio da instituição, que agrega importância ao documento. Nota-se que, no caso de Orestes, estudante do 3 o ano do curso secundário, a assinatura do pai não foi requerida, o que demonstra a responsabilidade a ele atribuída. 
Abaixo do nome Instituição Santa Maria, segue em letras menores "Com inspeção permanente (Decreto federal n. 481, de 9 de dezembro de 1935)" (IHGPR, 1940). Mas era o regulamento interno do Instituto que ditava as normas para que a instituição pudesse se tornar referência confessional. Segundo Viñao-Frago (2008), por meio desse tipo de material, pode-se aproximar da transmissão das ideologias, bem como conhecer as normativas que permeavam uma determinada instituição. Para tanto, na Caderneta Escolar Instituto Santa Maria (IHGPR, 1940) constava, dentre os nove regulamentos do aluno,

3. ${ }^{\circ}$ - A Religião sendo a base da verdadeira educação, será ensinada diariamente e a frequência à missa aos domingos e dias santos é obrigatória na Capela do Instituto; $4 .^{\circ}$ - A confissão e comunhão indispensáveis ao cristão que quer atingir a plenitude da sua vida moral, serão facultadas semanalmente aos alunos (IHGPR, 1940).

Por meio das palavras expressas no regulamento do ano de 1940 e a julgar pelos Irmãos que ministravam as aulas, o ensino era direcionado à manutenção dos valores católicos.

As demais normas do regulamento perpassavam questões comportamentais, penalidades e avaliativas da instituição. As justificativas de faltas; as lições orais e as periodicidades; o quadro de honra às melhores notas. Também eram temas da caderneta os principais deveres do aluno: obediência e respeito aos professores; o silêncio e guardar a ordem; a atenção às aulas; o asseio com os materiais e com o estabelecimento. As penalidades: repreensão particular; repreensão pública; lição a escrever; lição a estudar; privação de recreio; retardamento da saída; aviso aos pais; suspensão por vários dias; exclusão definitiva. Quanto às exclusões definitivas, só poderiam ser decididas pelo reitor e estavam reservadas em casos de roubo; atos de imoralidade; desobediência formal; preguiça habitual e frequência irregular. Por último, a caderneta trazia no regulamento o quadro de notas atribuídas: 100, distinção; 95 a 80, ótimo; 75 a 60, bom; 55 a 40, regular; 35 a 20, ruim; 10 a 0, péssimo.

Entretanto, as normativas que constam na caderneta não representam de forma fidedigna o que realmente ocorria na instituição. É preciso atentar-se que a caderneta fazia parte de um discurso e de uma imagem que a instituição gostaria de forjar e que poderia não condizer com a realidade das práticas vivenciadas. No entendimento de Viñao-Frago (2008), para se aproximar da "caixa-preta" escolar e assim ter um retrato mais fiel entre as normativas e ao que 
se era praticado, é preciso ter acesso aos cadernos dos alunos, material que pode desvelar os desvios e as ações involuntárias.

\section{A necessidade de mudança}

Com o passar dos anos, a sede localizada na Rua XV de Novembro tornou-se pequena para os projetos instituicionais maristas e para atender à demanda direcionada à educação por parte da população, diante da ineficácia do Estado em fornecer o serviço gratuito. De acordo com Ribeiro e Vieira (2018), desde os anos de 1920, as instituições particulares atendiam a uma parcela considerável de alunos. $\mathrm{O}$ aumento do número de alunos pode ser percebido na Tabela 1.

Tabela 1 - Número de alunos do Colégio Santa Maria, por ano

\begin{tabular}{c|c}
\hline Ano & № Alunos \\
1925 & 102 \\
1930 & 300 \\
1944 & 580 \\
1950 & 880 \\
1963 & 1000 \\
1965 & 1300 \\
1975 & 2200 \\
1985 & 3400 \\
\hline toras, com base em dados do jornal Gazeta do Povo (COLÉGIO, 1985).
\end{tabular}

A tabela demonstra o aumento de alunos que a instituição recebeu, ocorrido de forma gradativa após os anos 1950. No entendimento de Romanelli (2017), a Constituição de 1946 fazia uma concessão significativa de benefícios à iniciativa privada, no que se refere à liberdade de ensino, ao mesmo tempo em que desonerava o papel do Estado em proporcionar e garantir a educação gratuita e laica. No que se refere a essa questão, os trechos da Constituição dos Estados Unidos do Brasil, de 18 de setembro de 1946, dispõem que a educação "[...] é direito de todos e será dada no lar e na escola; Art. 167 - O ensino dos diferentes ramos será ministrado pelos poderes públicos e é livre a iniciativa particular, respeitada as leis que o regulem" (BRASIL, 1946). Romanelli (2017) continua sua análise com dados que corroboram com sua perspectiva: no ano de 1965, o número de matriculados na educação básica no ensino particular era superior ao 
público. Assim, a ineficácia do Estado em fornecer educação gratuita para todos pode ser indicada como um dos fatores para o aumento exponencial do crescimento no número de alunos na instituição Santa Maria. É preciso lembrar, no entanto, que a clientela do Colégio Santa Maria não seria a mesma da escola pública, ainda que o Estado atendesse à demanda e ofertasse educação gratuita para todos.

O aumento do número de alunos do Colégio Santa Maria ocorreu em virtude de diversos fatores, entre eles o nível de ensino, a seriedade do trabalho dos Irmãos, o estímulo aos valores cristãos, entre outros. Vieira (2014) explica que a pedagogia de Champagnat influenciou escolas em quase 80 países, mas que essa proposta não nasceu pronta e, sim, “[...] foi sendo elaborada pouco a pouco, por diversas gerações de educadores, que a enriqueceram com sua experiência ao longo dos anos" (VIEIRA, 2014, p.24). Por essa perspectiva, compreendemos que o trabalho dos Irmãos consolidou e constituiu a proposta pedagógica de Champagnat ao longo dos anos, conferindo, assim, credibilidade à escola junto à sociedade, que se alinhava com os valores ensinados.

Desde a implantação do primeiro colégio, a instituição vivenciou várias reformas educacionais, o que exigiu mudança também da proposta curricular. Destaca-se que até a reforma Capanema, que aconteceu em 1942, todas as diretrizes para as escolas na cidade de Curitiba partiam do Ginásio Paranaense (seção de externato e internato), ou seja, até as escolas particulares seguiam as mesmas regras. Nesse período, as escolas particulares deviam requerer a sua oficialização mediante algumas exigências, como:

Art. 45. I - Dispor de instalações, de edifícios e material didático, que preencham os requisitos mínimos prescritos pelo Departamento Nacional do Ensino; II - Ter corpo docente inscrito no Registro de Professores; III - Ter regulamento que haja sido aprovado, previamente pelo Departamento Nacional do Ensino; IV - Oferecer garantias bastantes de funcionamento normal pelo período mínimo de dois anos.

Art. 46. Satisfeitas as condições do artigo anterior e paga a quota anual mínima de inspeção, ficará o estabelecimento em regime de inspeção preliminar por prazo não inferior a dois anos (BRASIL, 1942).

Após a Reforma de 1942, as escolas particulares passaram a ter autonomia, desde que seguissem as regras nacionais quanto à documentação e ao currículo. Foi nessa linha do tempo 
que as duas unidades Maristas se constituíram e consolidaram seu atendimento na capital do Paraná.

Com o crescimento no número de alunos, de 100 para 2.200 em 1975, a sede da Rua XV de Novembro ficou inadequada. Porém, para explicar sobre a necessidade de uma nova sede, o Irmão Celedônio Cruz elucidou para o jornal Estado do Paraná, em 23 de fevereiro de 1980, que com "[...] o crescimento da cidade o Santa Maria ficou espremido" e complementava que havia "[...] se tornado impossível manter um colégio no centro", pois havia "[...] muito barulho, problemas de trânsito e estacionamento, além da falta de espaço, já que" contavam "[...] com mais de dois mil alunos" (QUEM..., 1980). Nas palavras de Celedônio, subentende-se que o problema foi imposto pelo crescimento da cidade e também pelo aumento do número de alunos matriculados na instituição.

Por meio dos jornais da época, podemos perceber que os Irmãos Maristas investiram em veiculação midiática para atrair mais alunos. A inauguração da nova sede marcou presença nos veículos impressos de maior circulação da cidade. No jornal Gazeta do Povo, veiculado em 14 de fevereiro de 1985, foi publicado que o Colégio Santa Maria se situava:

[...] instalado em um moderno complexo educacional ao lado do parque São Lourenço, numa área de 56 mil metros quadrados com toda a infraestrutura educacional, como sistema de circuito interno de televisão, computadores, laboratórios e bibliotecas central e infantil, 68 salas de aula, divididas em dois prédios (um especial para a Pré-Escola e outro para o 1으 e 2으 Graus), auditório para 1300 pessoas e plena assistência pedagógica, psicológica, espiritual e religiosa (COLÉGIO..., 1985).

No jornal da cidade, intitulado Folha de Curitiba, com data de 17 de fevereiro de 1984, foi publicada a abertura do novo Colégio Santa Maria, chamando a atenção para um conceito de inovação, criatividade e foco na formação para a vida. O conceito utilizado quanto à modernidade foi marcador em todos os anúncios de jornais. Abaixo, outro recorte de jornal com o mesmo marcador. 
Figura 3 - Foto na qual aparecem as novas instalações do Colégio Santa Maria

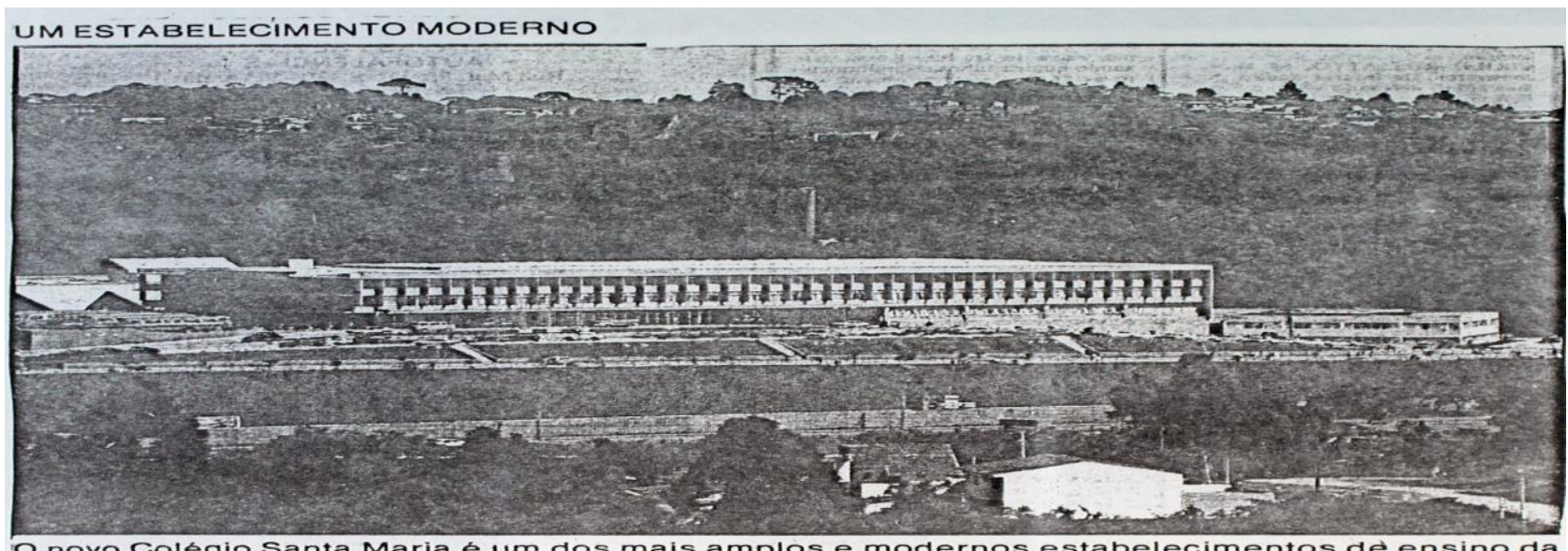

Anovo Colégio Santa Maria é um dos mais amplos e modernos estabelecimentos de ensino da

Fonte: Imagem publicada no jornal Gazeta do Povo, de 26 de fevereiro de 1984, disponível no acervo do memorial Marista da Província Brasil Centro-Sul.

A notícia acima foi publicada pela Gazeta do Povo no dia 26 de fevereiro de 1984 (UM ESTABELECIMENTO..., 1984), trazendo como chamada a modernidade da América Latina, o novo Colégio Marista em Curitiba. Em grande medida, as reportagens referiam-se à modernidade emplacada quanto à estrutura e à proposta anunciada, enquanto as questões relacionadas aos valores e à missão Marista não eram enfatizadas nas notícias de jornais. Dessa forma, entendemos que, na década de 80 do século $X X$, as características que mais importavam ser ressaltadas eram a modernidade das instalações e o tamanho da estrutura para atendimento aos alunos e não os valores cristãos das escolas confessionais do início da fundação.

Enfatizar a estrutura e a modernidade, e não os valores da escola confessional, pode ser compreendido à medida que se entende que o currículo dessas instituições paulatinamente foi se tornando incompatível com os desejos de parte da população, que passou a enxergar a escola como forma de ingresso no mercado de trabalho. Buffa (2011) complementa que principalmente as escolas confessionais administradas pela Igreja Católica perderam parte de seu prestígio ao priorizarem o ensino religioso em detrimento aos ensinos ligados a carreiras profissionais, mas não se pode generalizar esse pensamento para todas as escolas confessionais.

É preciso lembrar que as famílias cujos filhos compunham a clientela das escolas confessionais, do porte do Santa Maria, não desejavam a profissionalização dos filhos no nível médio, o que havia se tornado obrigatório pela Lei n. ${ }^{\circ}$ 5.692/71 (BRASIL, 1971). Tanto isso era verdade que a própria Lei . $^{\circ} 5.692 / 71$ foi alterada nos anos 80 para inserir o ensino 
propedêutico e liberar as escolas da obrigatoriedade da profissionalização (BRASIL, 1982). ensino médio, para essas famílias, era visto como preparação para o ensino superior e as majestosas instalações acrescidas à tradição de ensino tornavam-se um bom chamariz. Dessa maneira, parece-nos que, nos meios de comunicação de 1980, os Irmãos Maristas procuraram representar sua imagem ligada às modernas estruturas em consonância aos desejos de sua clientela.

No intuito de atender àquilo que a sociedade aspirava, também foram encontrados recortes de jornais quanto ao aceite de matrículas de meninas. Na cidade Curitiba, em 18 de fevereiro de 1979, o jornal Estado do Paraná publicava que o Santa Maria aceitaria meninas:

Depois de manter uma tradição de 54 anos, os Irmãos Marista do Colégio Santa Maria resolvem abrir suas portas para as meninas da cidade. Agora, elas poderão estudar naquela instituição de ensino, frequentando os cursos do primeiro e segundo graus. Na segunda-feira passada houve uma recepção às novas estudantes, dando início ao ano letivo [...] Conforme falou o funcionário, a maior parte das alunas veio de colégios também fechados, como o Divina Providência, Cajuru ou Sagrado Coração de Jesus. As novas alunas matriculadas são em número de 110 , fora as do período da tarde. A decisão de abertura coube ao diretor do colégio, Celedônio Cruz, que assumiu este cargo em 78. Para Curitiba trouxe sua larga experiência adquirida em outras escolas do Brasil (SANTA MARIA..., 1979).

A manchete de jornal pontuava o posicionamento dado pela direção da instituição de que as mudanças eram inevitáveis, uma vez que "[...] foi sendo exigida, mais e mais, uma modernização nos métodos de ensino. Além disto, estava ocorrendo uma grande evasão de estudantes, quando aprovados na oitava série, ingressando no curso de 2o grau". No entendimento da direção, a evasão se "[...] dava justamente na idade em que os meninos passavam a sentir necessidade de maior contato com as meninas e, quando isolados, isso acabava acarretando problemas psicológicos causados pela carência de afeto e amizade com o sexo oposto" (SANTA MARIA..., 1979). Na explicação dada pela direção da instituição, para o aceite de matrículas de estudantes do sexo feminino, é possível encontrar motivos didáticos, no sentido de modernização do ensino; afetivos, no que diz respeito ao cuidado com o bem-estar psicológico dos meninos; e ponderações econômicas, no que tange à evasão de alunos para outros colégios. 
Entretanto, a segregação sexual nas escolas foi uma das amarras sofridas pela educação formal das mulheres, que foi se desprendendo no decorrer dos anos. De acordo com Rosemberg (2016), durante o século XX, esses entraves foram sendo rompidos:

[...] a segregação sexual das escolas, interditando a educação mista; o ideário de que a educação de meninas e moças deveria ser mais restrita que a de meninos e rapazes em decorrência da saúde frágil, sua inteligência limitada e voltada para a "missão" de mãe; o impedimento à continuidade dos estudos secundários e superiores para as jovens brasileiras (ROSEMBERG, 2016, p.334).

Nas instituições públicas de ensino do Estado era comum o ensino para classes mistas desde várias décadas atrás, enquanto nas instituições confessionais foram as necessidades econômicas que alteraram as práticas. No entendimento de Rosemberg (2016), não era uma prática recomendável manter moças e rapazes num mesmo espaço de convivência para as escolas mantidas pela Igreja Católica, mas, por razões econômicas, a Igreja Católica inaugurava, nas pequenas cidades, classes mistas diante do reduzido número de alunos. Por esse prisma, compreendemos que por razões de redução de custos e incremento na receita da Instituição, foi necessário formar meninas e meninos no mesmo ambiente.

As instituições Maristas procuraram manter suas tradições enquanto conseguiram. 0 Colégio Marista Paranaense, desde 1943, funcionou apenas como internato para meninos, o que não estimulava a convivência entre os sexos. Mais tarde, porém, a oferta do internato foi descartada e o colégio iniciou sua primeira turma mista em 1975, com a admissão da primeira menina. Quanto ao Santa Maria, foi uma das últimas instituições Maristas a aceitar matrículas de meninas, em 1979.

De acordo com os discursos proferidos pelo Irmão Celedônio Cruz, os colégios novamente tentavam acompanhar as mudanças solicitadas pela sociedade. As famílias reclamavam porque o Santa Maria não aceitava meninas, ainda mais considerando que outros colégios religiosos para moças estavam fechando em Curitiba. Era necessário mudar algumas práticas para atender à grande fatia do mercado que se fazia presente. 


\section{Considerações finais}

Os registros históricos do Instituto permitem-nos aferir que a instituição foi, ao longo da história, adequando-se ao sistema brasileiro, à legislação brasileira e a todas as reformas educacionais. Pudemos identificar que o Memorial Marista, bem como os demais documentos que representam a instituição, constrói uma memória sobre a atuação da Instituição Marista na educação.

Os documentos analisados constituem vestígios históricos sobre a educação Marista na cidade de Curitiba. As fontes advindas das instituições Maristas representam Marcelino Champagnat como religioso motivado a fundar a instituição voltada a uma educação pautada na manutenção da moral e dos bons costumes. Os documentos escritos por Marcelino são representados como direcionadores para a abertura das novas escolas, de maneira a alinhar o pensamento do fundador com os demais Irmãos.

Nas fontes, os primeiros registros dos Irmãos no Brasil são datados de 1897, na cidade de Congonhas do Campo, no estado de Minas Gerais, sendo suas primeiras ações o recrutamento de jovens para serem formados conformes as diretrizes Maristas. Na cidade de Curitiba, a chegada dos Maristas se dá no ano de 1924 e os documentos representam o momento ligado aos interesses e ao consentimento da Igreja Católica. A Instituição Santa Maria foi instalada em local privilegiado no centro da cidade, em majestoso prédio, em área nobre da cidade.

Com o passar dos anos, mudanças no local e nas estratégias da instituição foram representadas. Nos anos iniciais da instituição, era necessário sair em busca de educadores e de alunos. Nos anos de 1940, eram enfatizados os valores confessionais e as normativas nos documentos de alunos, ao passo que, à medida que o currículo confessional foi perdendo o prestígio na sociedade, o discurso foi se alterando e a modernidade das instalações foi ganhando seu espaço no discurso.

Com a expansão no número de alunos, a mudança de sede tornou-se uma necessidade, assim como novas medidas nas práticas educativas. Nos jornais, Celedônio Cruz procurou enfatizar as modernidades das estruturas e a aceitação de meninas dentro do colégio. Dessa forma, podemos identificar que cada documento traz consigo uma memória carregada de intencionalidades daqueles que a forjaram e marcas do contexto histórico no qual ela foi constituída. 
Ademais, identificamos, no processo de pesquisa, cadernos de anotação que não faziam parte do objeto de pesquisa, mas que podem ser utilizados em estudos futuros pelo ineditismo quanto às fontes.

\section{Referências}

ALVES, M. Missão educativa marista. (2011). Disponível em:

http://www.pucrs.br/reflexoes/encontro/2001-3/documentos/05-Universidade-e EducacaoMarista-Manoel-Alves.pdf. Acesso em: 10 jan. 2019.

BONATO, I. F. Origem do juvenato de Curitiba 1924. Curitiba: 19[?]. Arquivo Memorial Marista.

BRASIL. Decreto-Lei n. ${ }^{\circ}$ 4.244, de 09 de abril de 1942. Lei orgânica do ensino secundário. Diário Oficial da União. Rio de Janeiro, DF. 10 de abril de 1942. Disponível em:

http://www.planalto.gov.br/ccivil_03/decreto-lei/1937-1946/Del4244.htm. Acesso em: 9 jan. 2019.

BRASIL. Constituição da República dos Estados Unidos do Brasil de 1946. Diário Oficial da União. Rio de Janeiro, DF. 18 set. 1948. Disponível em:

http://www.planalto.gov.br/ccivil_03/constituicao/constituicao46.htm. Acesso em: 9 nov. 2019.

BRASIL. Lei n. ${ }^{\circ}$ 5.692, de 11 de agosto de 1971. Fixa Diretrizes e Bases para o ensino de $1 .^{\circ}$ e $2 .^{\circ}$ graus, e dá outras providências. Diário Oficial da União. Brasília, DF, 12 ago. 1971. Disponível em: https://www2.camara.leg.br/legin/fed/lei/1970-1979/lei-5692-11-agosto-1971-357752publicacaooriginal-1-pl.html. Acesso em: 27 abr. 2020.

BRASIL. Lei n. ${ }^{\circ}$ 7.044, de 18 de outubro de 1982. Altera dispositivos da Lei n. ${ }^{\circ} 5.692$, de 11 de agosto de 1971, referentes a profissionalização do ensino de $2 .^{\circ}$ grau. Diário Oficial da União. Brasília, DF. 19 out. 1982. Disponível em: https://www2.camara.leg.br/legin/fed/lei/19801987/lei-7044-18-outubro-1982-357120-norma-pl.html. Acesso em: 27 abr. 2020.

BUFFA, E. O público e o privado na educação brasileira do século XX. STEPHANOU, M. H.; BASTOS, M. H. C. (orgs.). Histórias e memórias da educação no Brasil: vol. III, século XX. 4. ed. Petrópolis, RJ: Vozes, 2011. p.53-67.

CARVALHO, M. M. C. A escola e a República. São Paulo: Brasiliense, 1989.

CERTEAU, M. DE. A escrita da história. Rio de Janeiro: Forense Universitária, 1982.

CHARTIER, R. As origens culturais da revolução francesa. Trad. George Schlesinger. São Paulo: Editora da Unesp, 2009. 
COLÉGIO Santa Maria comemora nesta sexta o $60^{\circ}$ aniversário. Gazeta do Povo, Curitiba, v.[s/i], n.[s/i], 14 fev. 1985, c.[s/i], p[s/i]. Acervo Casa da Memória de Curitiba.

FURET, J.-B. et al. Guia das escolas para uso nas casas dos pequenos irmãos de Maria: Documento do 2 Capítulo Geral do Instituto Marista. Trad. João José Sagin e Virgílio Josué Balestro. Brasília: UMBRASIL, 2009.

GIUSTO, L. DI. História do instituto dos irmãos maristas. São Paulo: FTD, 2007.

INSTITUTO HISTÓRICO E GEOGRÁFICO DO PARANÁ - IHGPR. Caderneta escolar Instituto Santa Maria: Coleção Pórcia Guimarães Alves, 1940.

LE GOFF, J. História \& memória. 7. ed. São Paulo: Unicamp, 2013.

QUEM compra o Santa Maria? Estado do Paraná, Curitiba, v. [s/i], n. [s/i], 23 fev. 1980, c. [s/i], p.[s/i]. Acervo Casa da Memória de Curitiba.

RAZZINI, M. P. G. Instrumentos de escrita na escola elementar: tecnologias e práticas. In: MIGNOT, A. C. V. (org.). Cadernos à vista: escola, memória e cultura escrita. Rio de Janeiro: EDUERJ, 2008, p.91-113.

RIBEIRO, A. F. M.; VIEIRA, A. M. D. P. Pórcia: arquivos de vida, formação e atuação. Curitiba: Appris, 2018.

ROMANELLI, O. O. História da educação no Brasil. 40. ed. Rio de Janeiro: Vozes, 2017.

ROSEMBERG, F. Mulheres educadoras e a educação de mulheres. In: PINSKY, C. B.; PEDRO, J. M. (orgs.). Nova história das mulheres no Brasil. 2. reimpr. São Paulo: Contexto, 2016. p.333-359.

SANTA MARIA aceita meninas. Estado do Paraná, Curitiba, v.[s/i], n.[s/i],18 fev. 1979, c.04-08, p.09. Acervo Casa da Memória de Curitiba.

SCHELBAUER, A. R.; CORRÊA, R. L. T. Povoar e escolarizar: história da expansão, dos modelos e modalidades de escola primária no Paraná (1930-1961). In: FURTADO, A. C.; SCHELBAUER, A. R.; CORRÊA, R. L. T. (orgs.). Itinerários e singularidades da institucionalização e expansão da escola primária no Brasil (1930-1961). Paraná: UEM, 2019, p.55-86.

SOBOUL, A. A revolução francesa. 7. ed. Trad. R. Silva. Rio de Janeiro: Bertrand Brasil, 1989.

UM ESTABELECIMENTO moderno. Gazeta do Povo, Curitiba, v. [s/i], n. [s/i], 26 fev. 1984, c. [s/i], p.[s/i]. Acervo do memorial Marista da Província Brasil.

UNIÃO MARISTA DO BRASIL. Projeto educativo do Brasil Marista: nosso jeito de conceber a Educação Básica. Brasília: UMBRASIL, 2010. 
VIEIRA, A. M. D. P. Instituições escolares: memória, fontes, arquivos e novas tecnologias. In: SILVA, J. C.; ORSO, P. J.; CASTANHA, A. P.; MAGALHÃES, L. D. R. (orgs.). História da educação: arquivos, instituições e memória histórica. Campinas: Alínea, 2013, p.65-77.

VIEIRA, A. M. D. P. A formação de professores e a pedagogia marista. In: CONGRESSO MUNDIAL DE UNIVERSIDADES CATÓLICAS - CMUC, 2014, Belo Horizonte. Anais [...]. Belo Horizonte: CMUC, 2014. p.23-31.

VIEIRA, A. M. D. P. Educação em Curitiba: trinta anos de políticas públicas. Curitiba: Appris, 2017.

VIÑAO-FRAGO, A. Os cadernos escolares como fonte histórica: aspectos metodológicos e historiográficos. In: MIGNOT, A. C. V. (org.). Cadernos à vista: escola, memória e cultura escrita. Rio de Janeiro: Ed UERJ, 2008, p.15-33.

Recebido em maio 2020.

Aprovado em abril 2021. 